
\title{
R Research Soure \\ Detection and Visualization of Manufacturing Errors of Internal Cavity Structural Parts
}

\section{Li-Ming Duan ( $\nabla$ duanliming163@163.com )}

Chongqing University https://orcid.org/0000-0001-7441-5266

\section{Lei Si}

Chongqing University

\section{Xue-Qing Luo}

Chongqing University

Jia-Hang Wu

Chongqing University

Cheng Fang

Chongqing University

Original Article

Keywords: CT image, error detection, inner cavity structure, visualization

Posted Date: December 28th, 2020

DOl: https://doi.org/10.21203/rs.3.rs-134823/v1

License: (c) (1) This work is licensed under a Creative Commons Attribution 4.0 International License. Read Full License 


\section{Abstract}

Aiming at the difficulty of manufacturing error detection of internal cavity structural parts, a detection method of common manufacturing error based on industrial CT images was proposed. Firstly, the image sequence of part scanned by an industrial CT machine is converted into a three-dimensional measurement model; Then, the registration of the three-dimensional measurement model with the original design model is completed; The surface information of the part is obtained by segmenting surfaces of the three-dimensional measurement model; Next, the datum surface is selected, the error value of the test surface is calculated after selecting datum surface; Finally, the detection result is obtained by comparing the error value with the tolerance value, analyzing the result and the areas that do not meet the tolerance requirements is visualized in the developed software system. The common manufacturing errors of complex inner cavity parts can be detected by the method, such as dimension error of length, planeness error, cylindricity error, parallelism and perpendicularity error of face-to-face, at the same time, it can intuitively show the area whose manufacturing errors in the cavity structure of the parts are not satisfied, which provides a basis for judging the quality of manufacturing and processing of parts.

\section{Full Text}

Due to technical limitations, full-text HTML conversion of this manuscript could not be completed. However, the latest manuscript can be downloaded and accessed as a PDF.

\section{Figures}




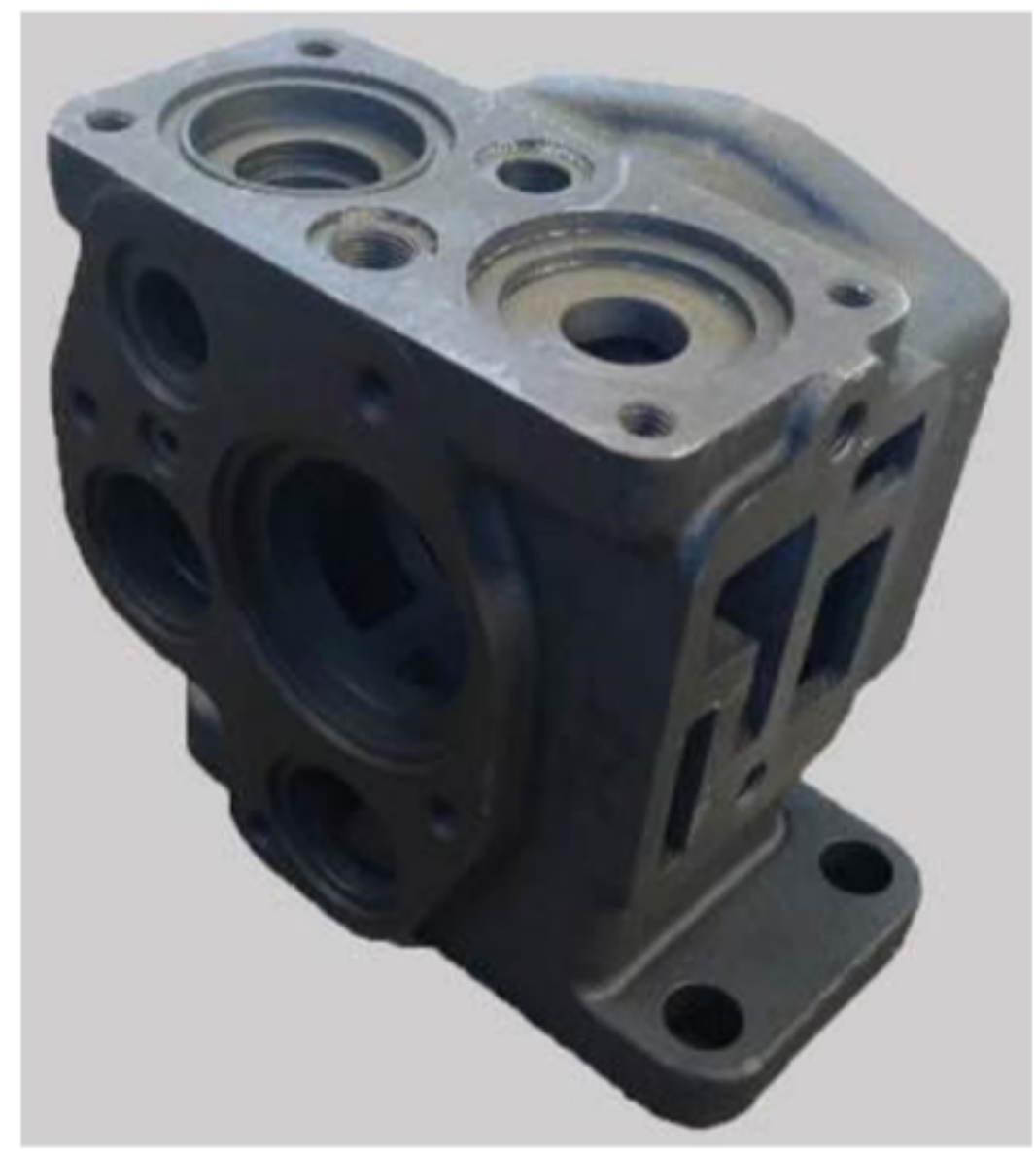

Figure 1

A Certain Type of Valve Body 

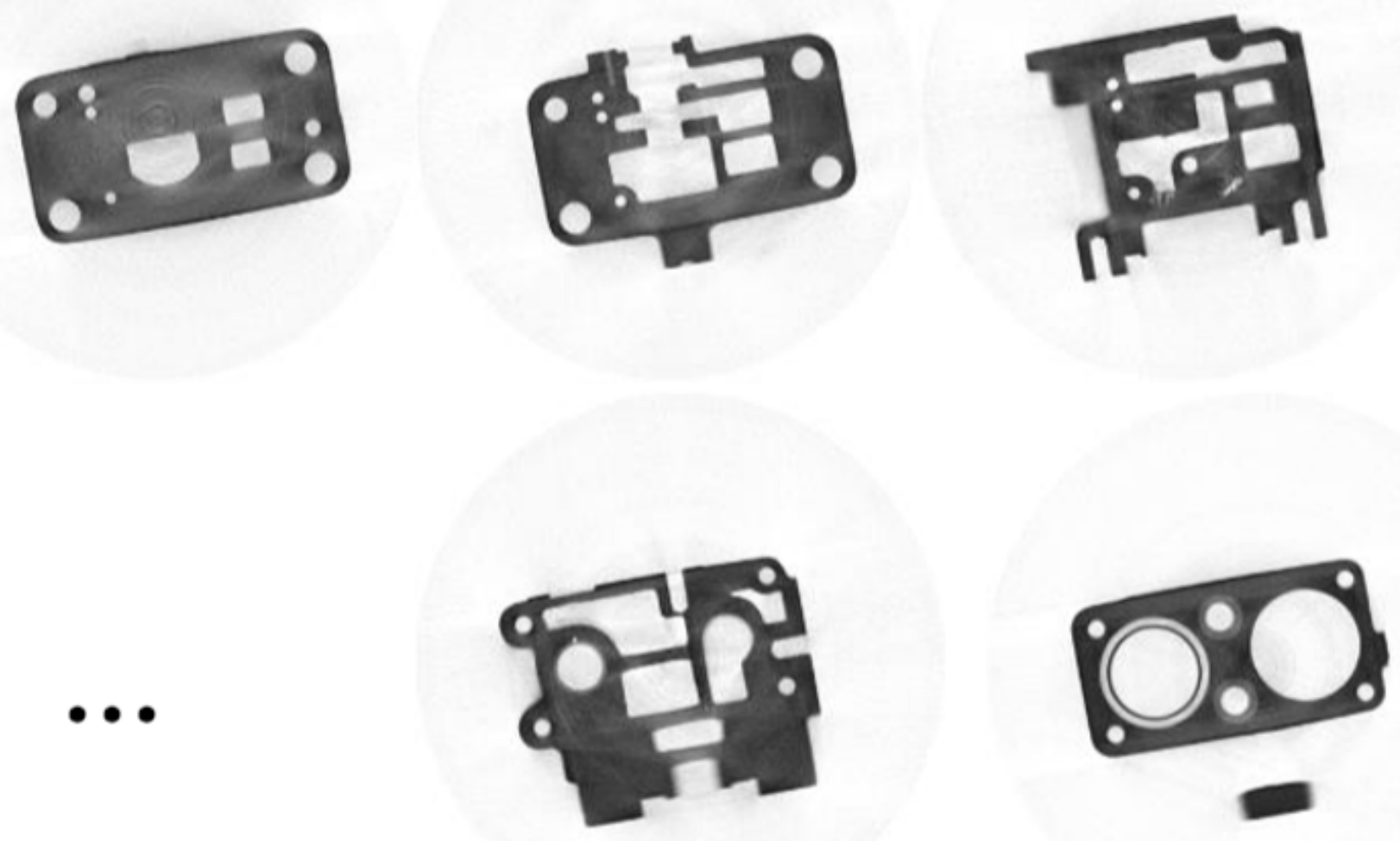

Figure 2

Sectional image sequence of valve body

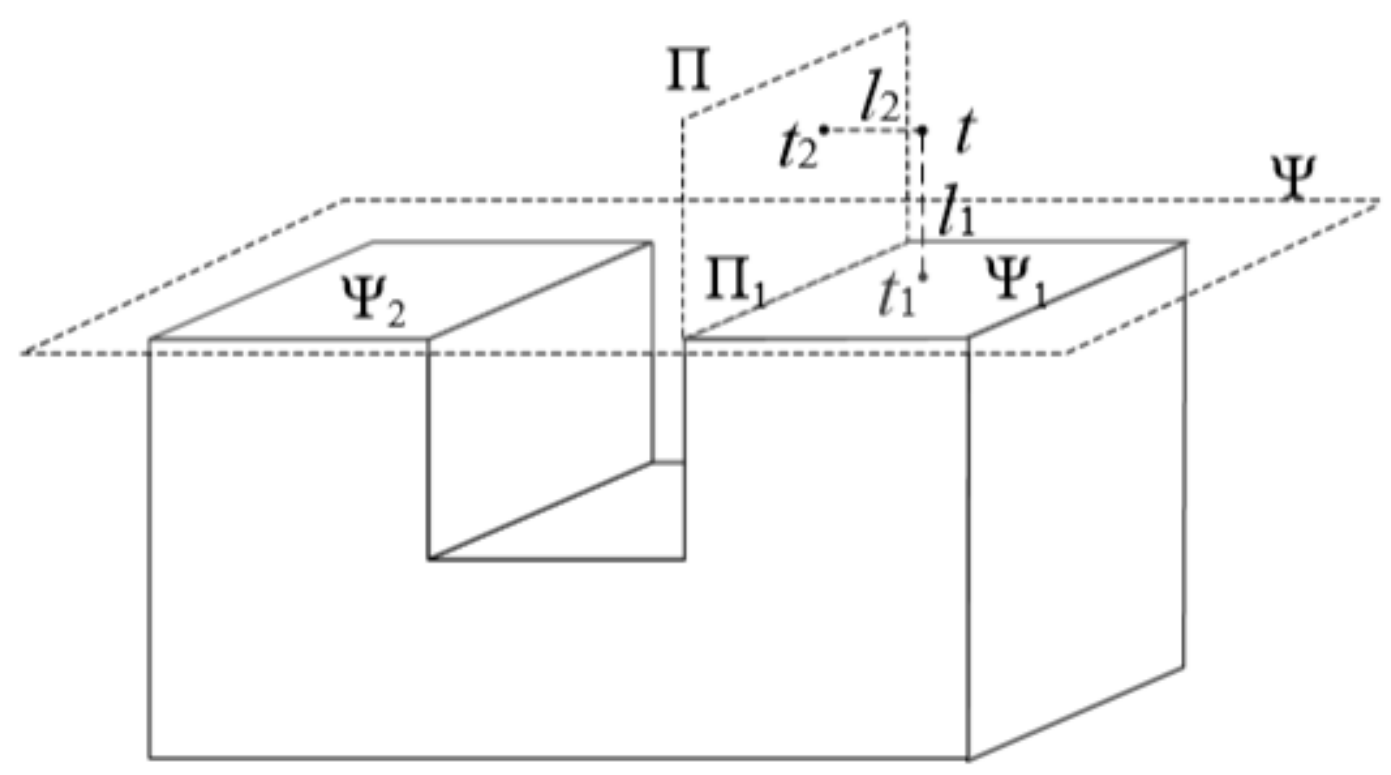

Figure 3 
A special case of attribution surface for the point

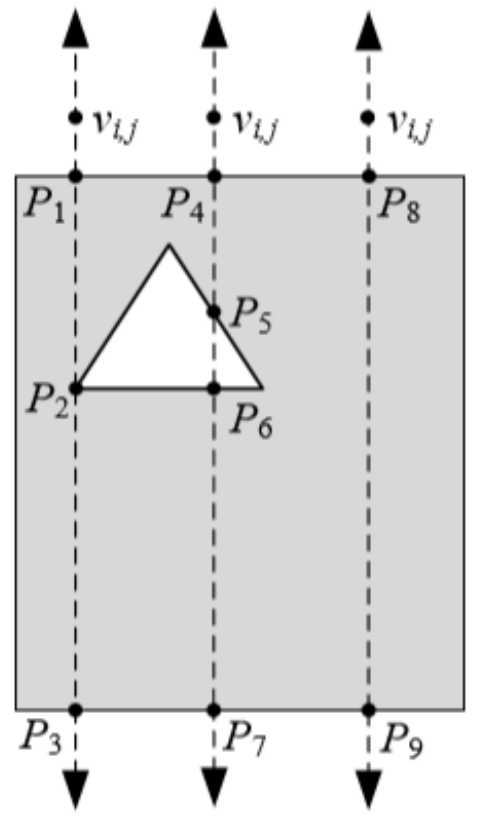

(a)

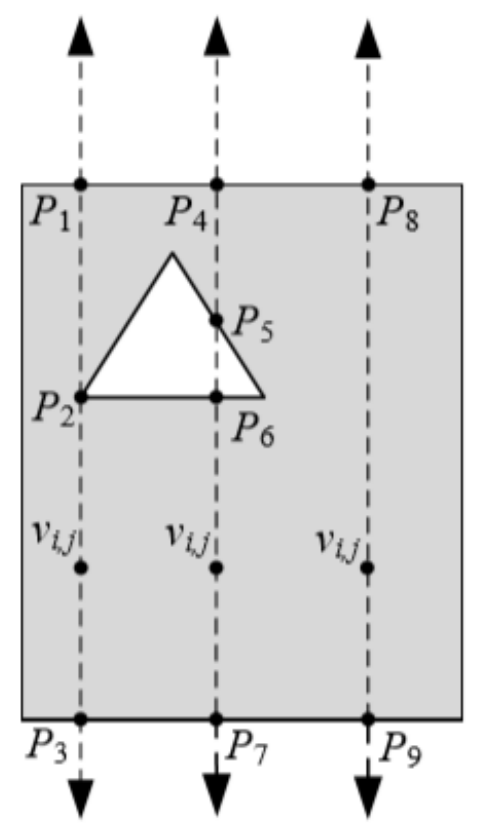

(c)

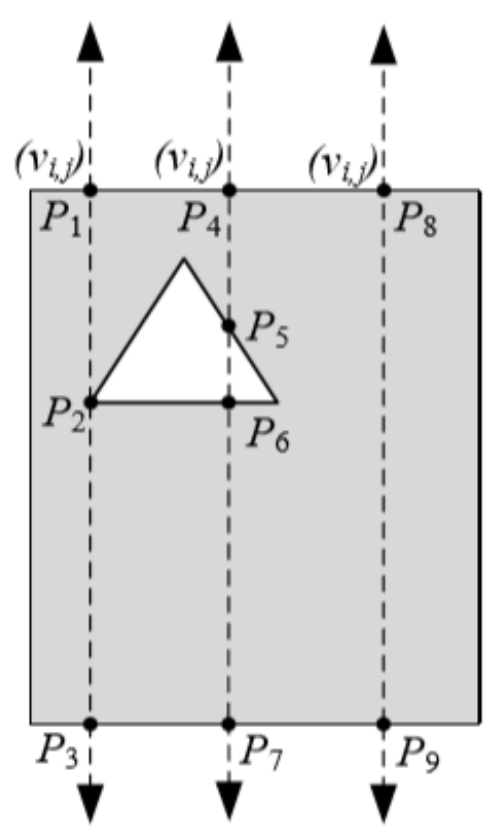

(b)

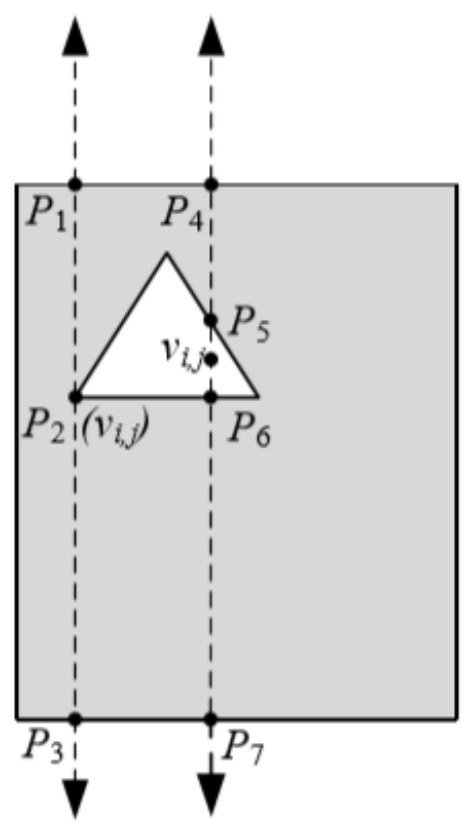

(d)

Figure 4

Location relationship between projection point and plane boundary 


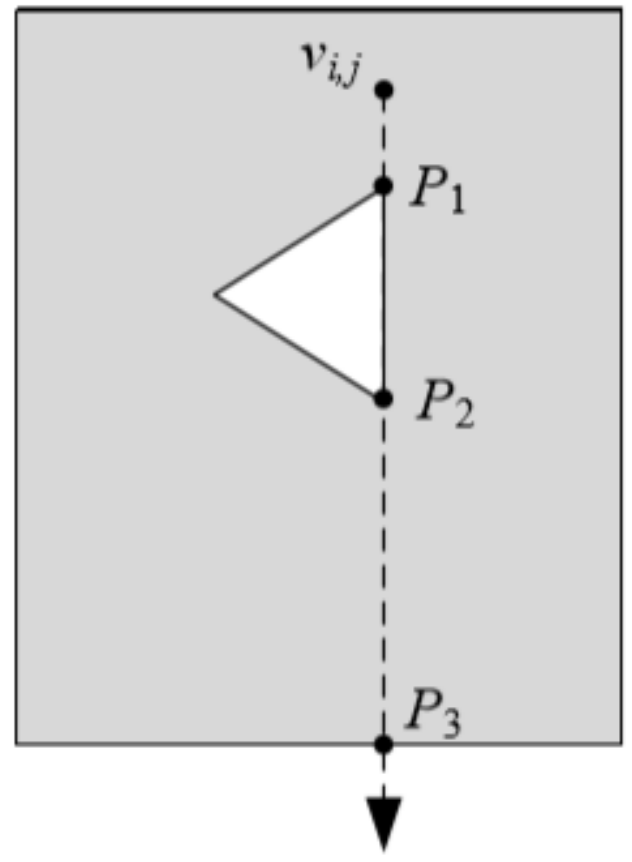

Figure 5

Rays coincide with plane boundaries 


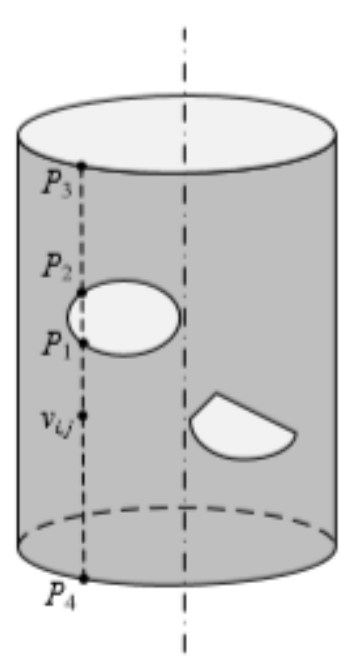

(a) Cylinder surface

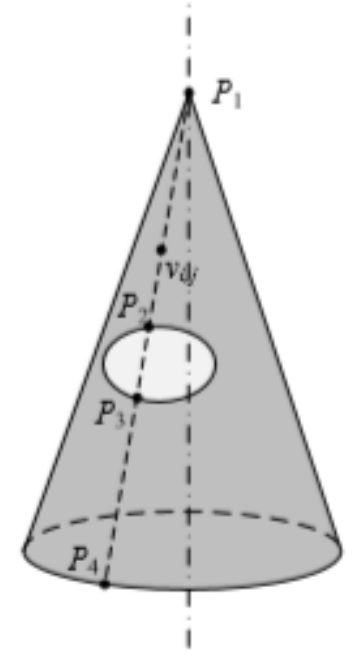

(b) Conical surface

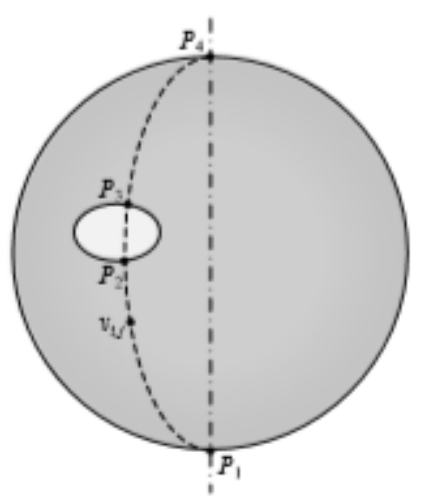

(c) Spherical surface

\section{Figure 6}

Location relationship between projection point and surface boundary 


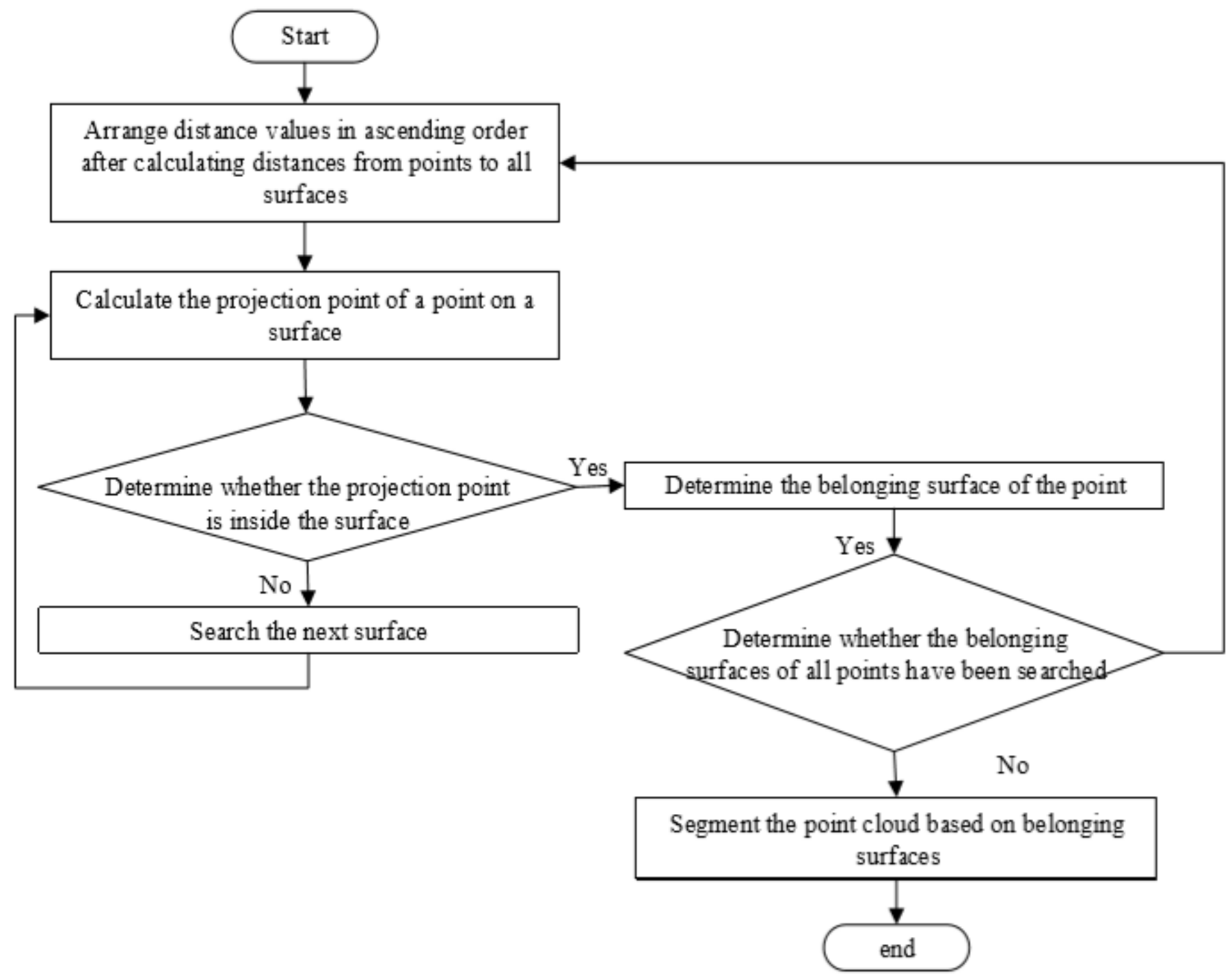

Figure 7

The flowchart of the point cloud segmentation

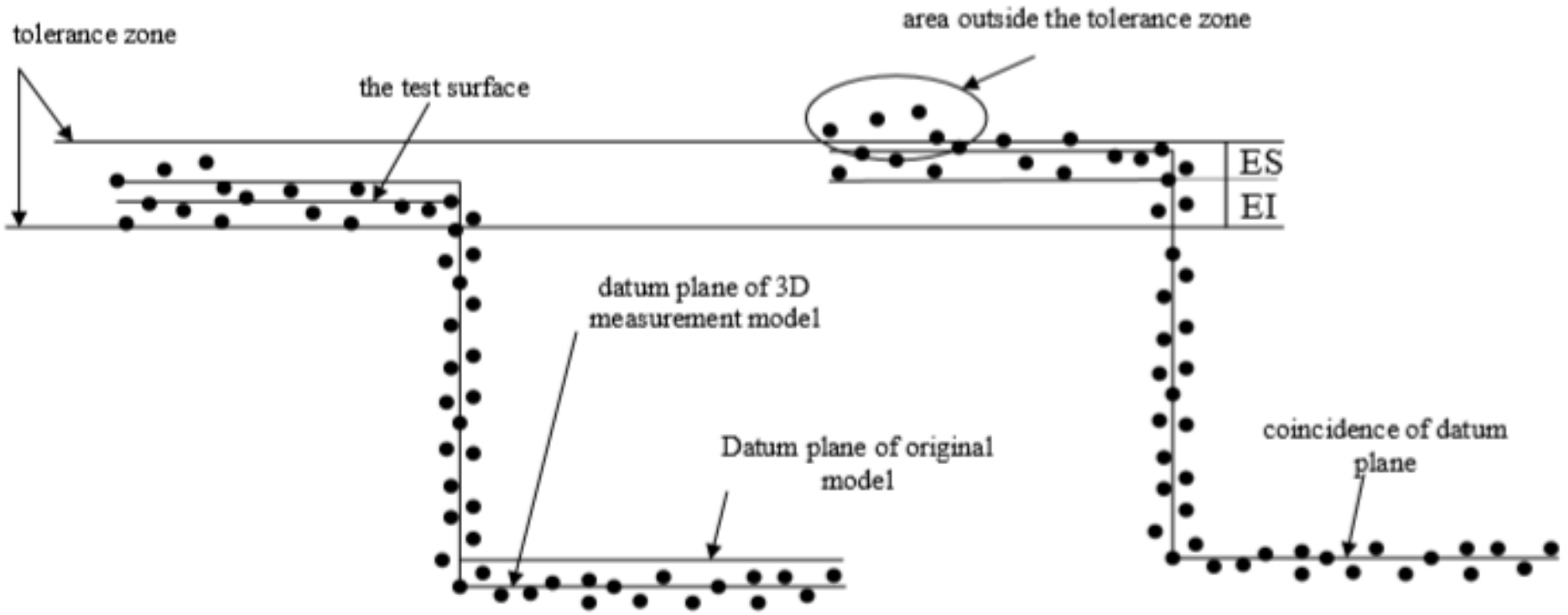


Figure 8

Coincidence of datum plane

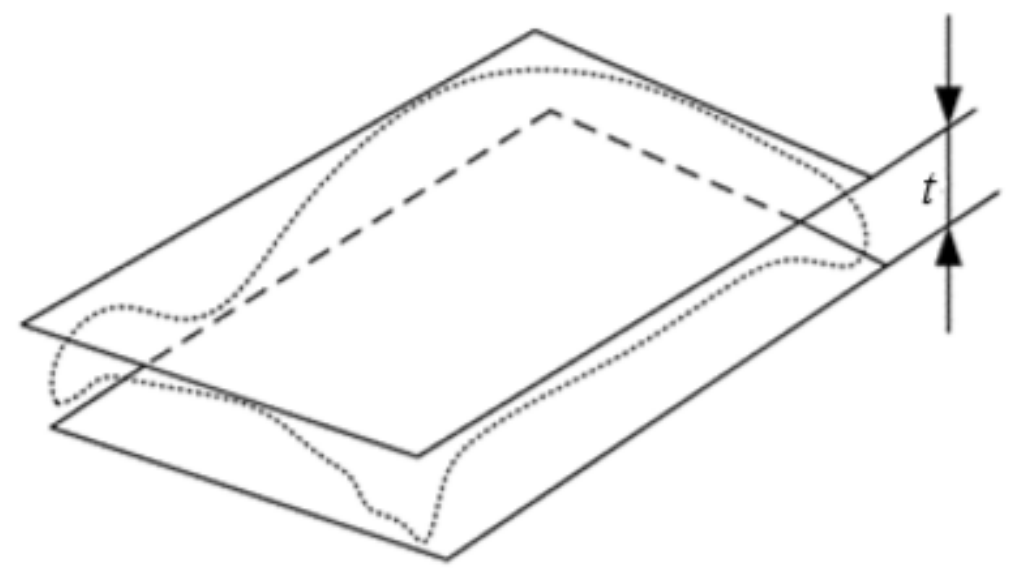

Figure 9

Planeness tolerance zone

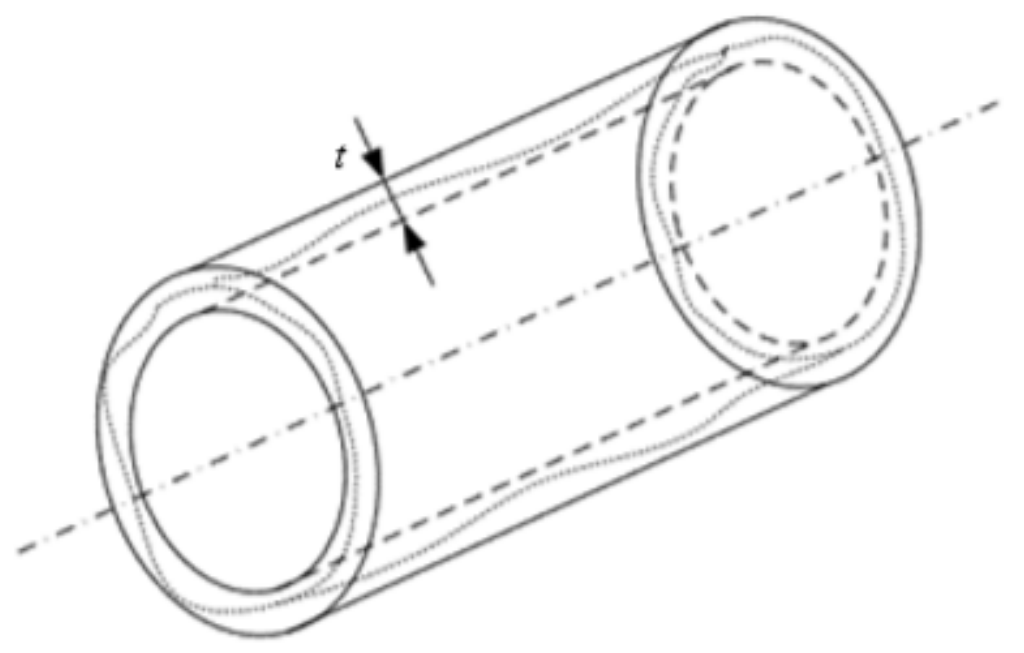

Figure 10

Cylindrical tolerance zone 


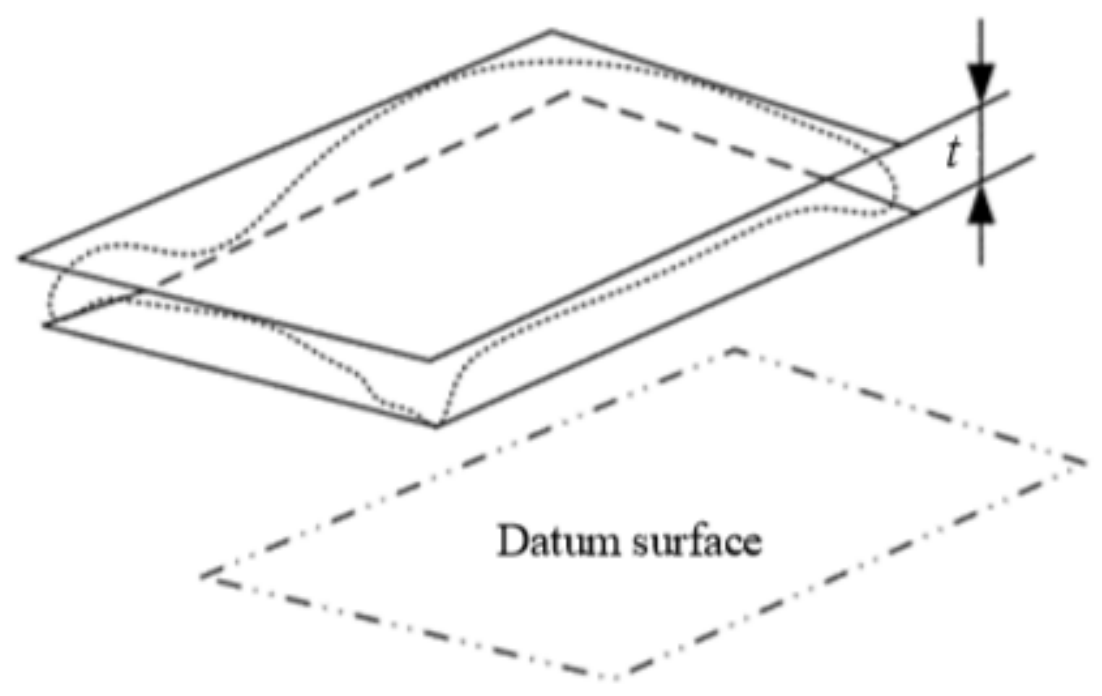

Figure 11

Parallelism tolerance zone

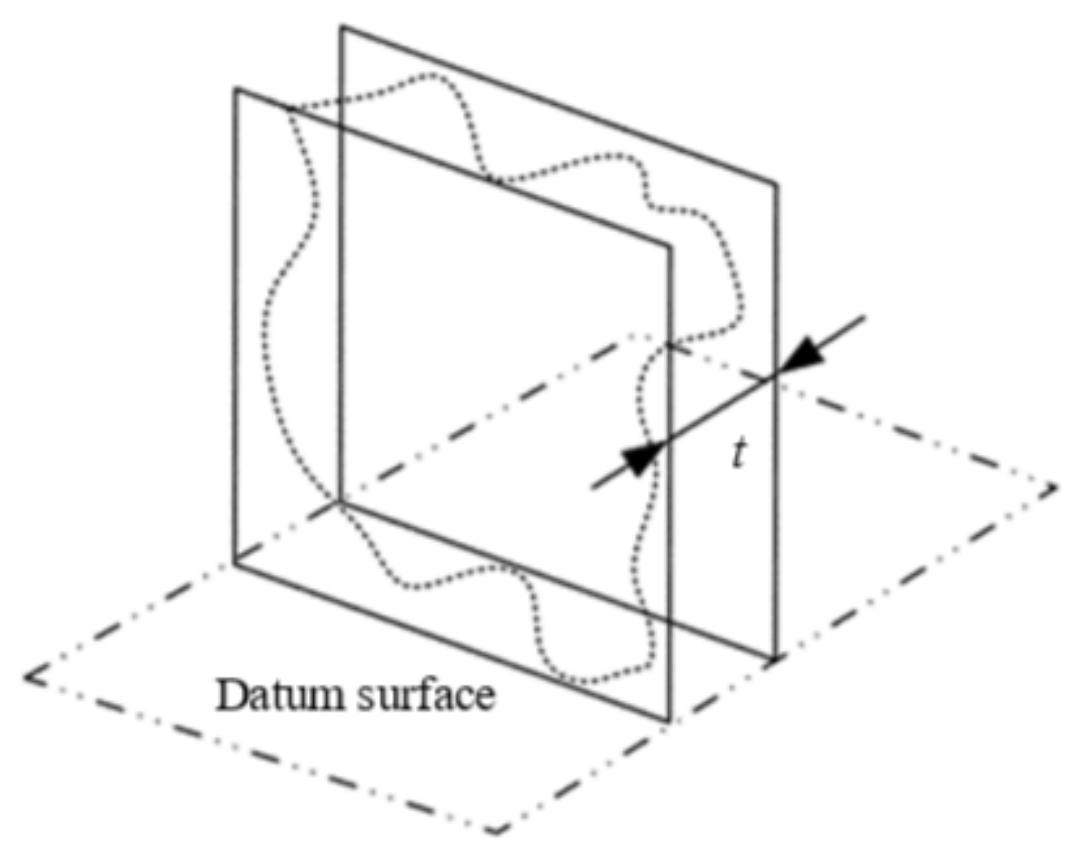

Figure 12

Verticality tolerance zone

Page 10/21 


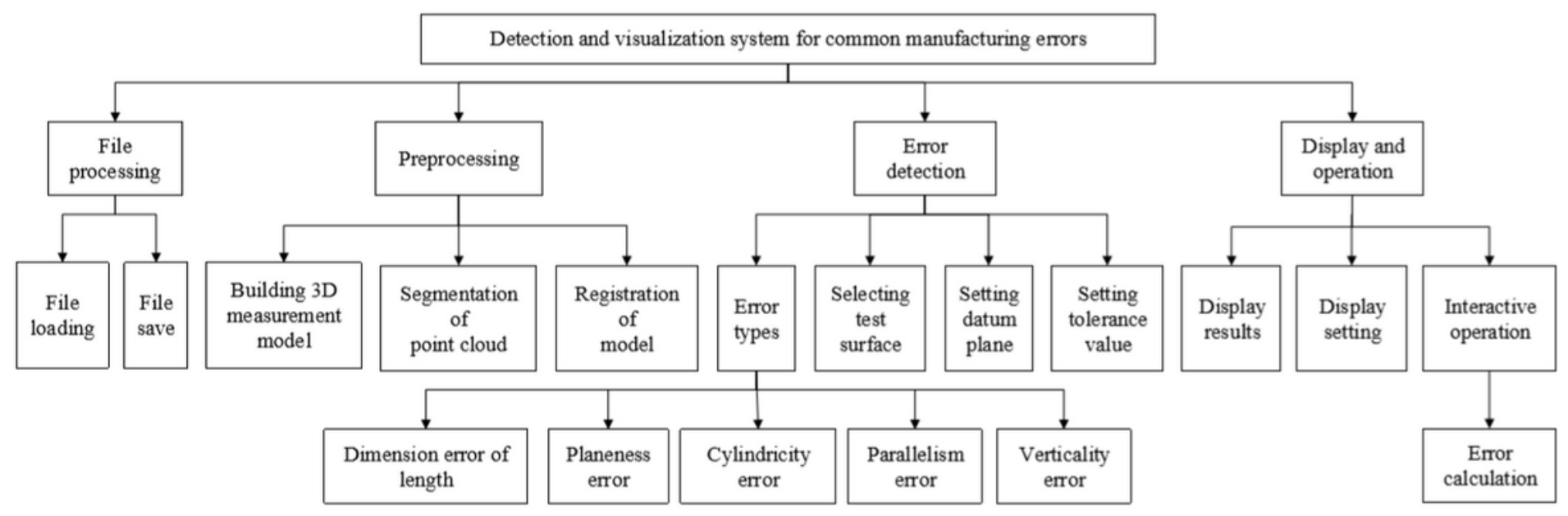

\section{Figure 13}

\section{Diagram of system function}

\begin{tabular}{|c|c|c|c|c|c|}
\hline Industrial CT image & Data loading & $\begin{array}{c}\text { 3D measurement } \\
\text { model }\end{array}$ & $\begin{array}{l}\text { Point cloud } \\
\text { segmentation }\end{array}$ & Model registration & Selecting error type \\
\hline Results display & display setting & $\begin{array}{l}\text { Analysis of test } \\
\text { results }\end{array}$ & Error calculation & $\begin{array}{l}\text { Selecting the test } \\
\text { surface }\end{array}$ & Setting the datum \\
\hline
\end{tabular}

\section{Figure 14}

Processing flow of system 
Detection and Visualization of $\mathrm{ME}$

File Edit Display Detection Help

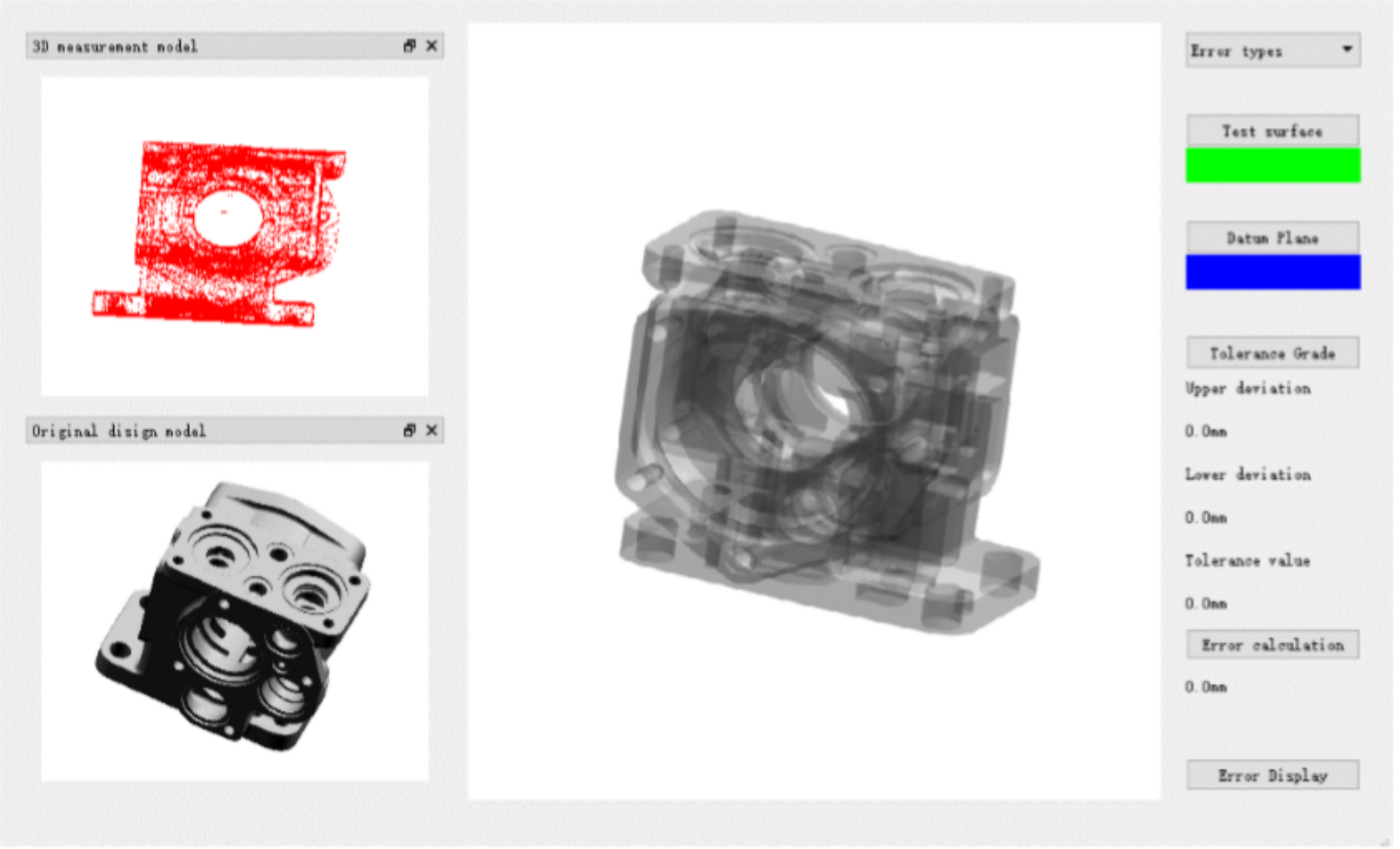

Figure 15

System interface 


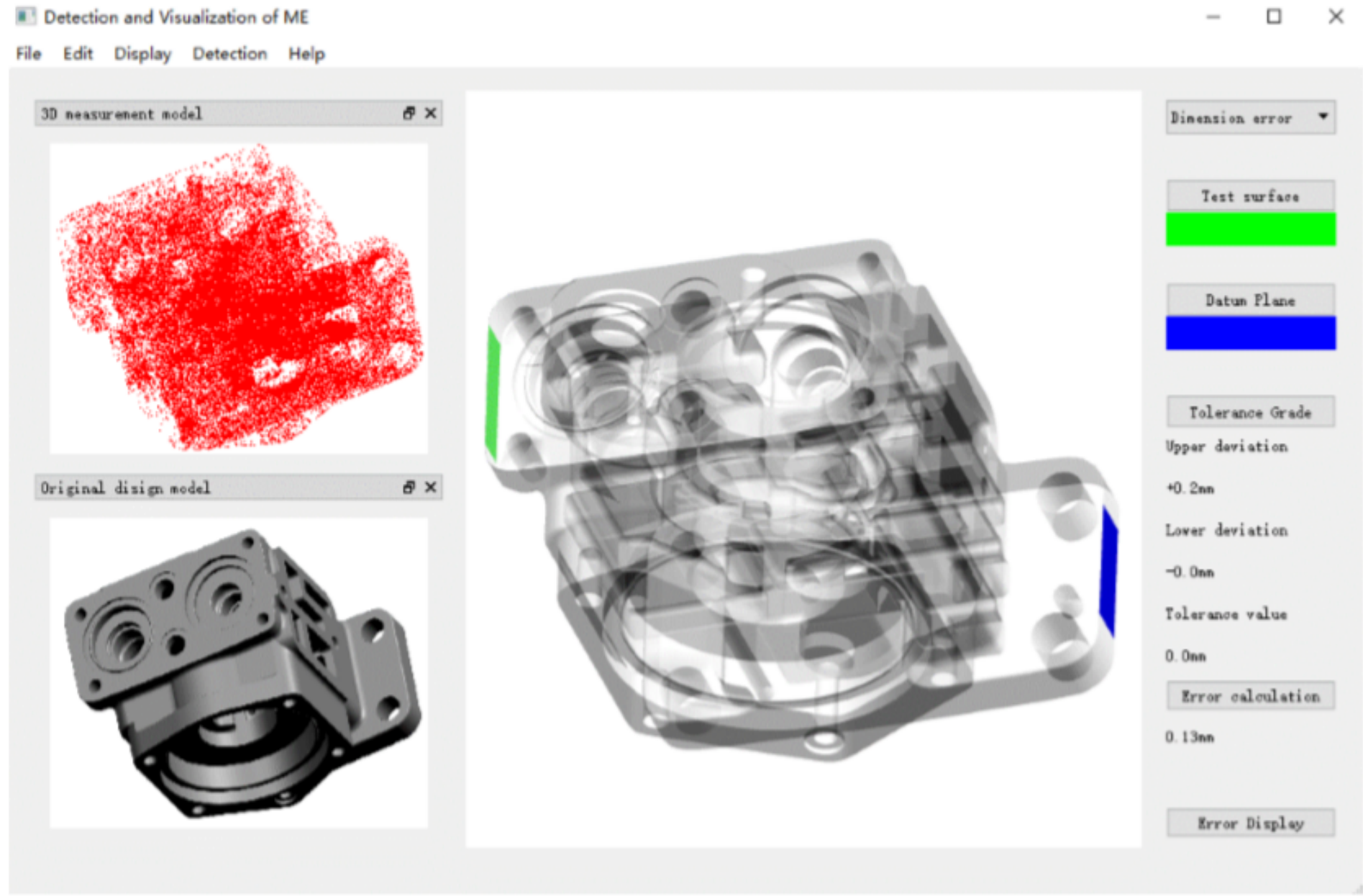

Figure 16

Dimension error analysis results of the length of the valve body 
File Edit Display Detection Help

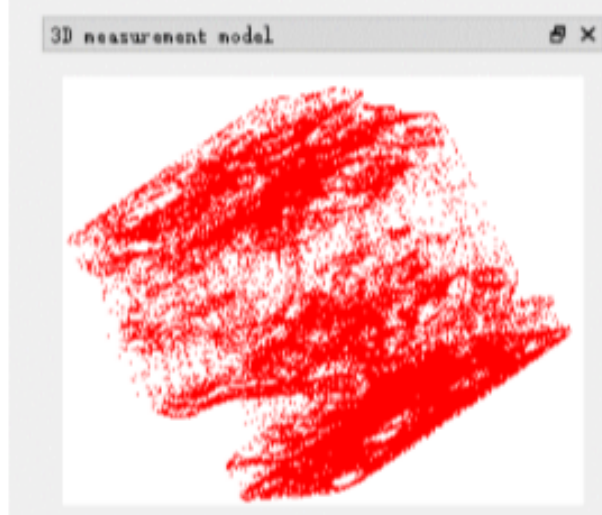

Orisinal disien nodel

$\theta \times$
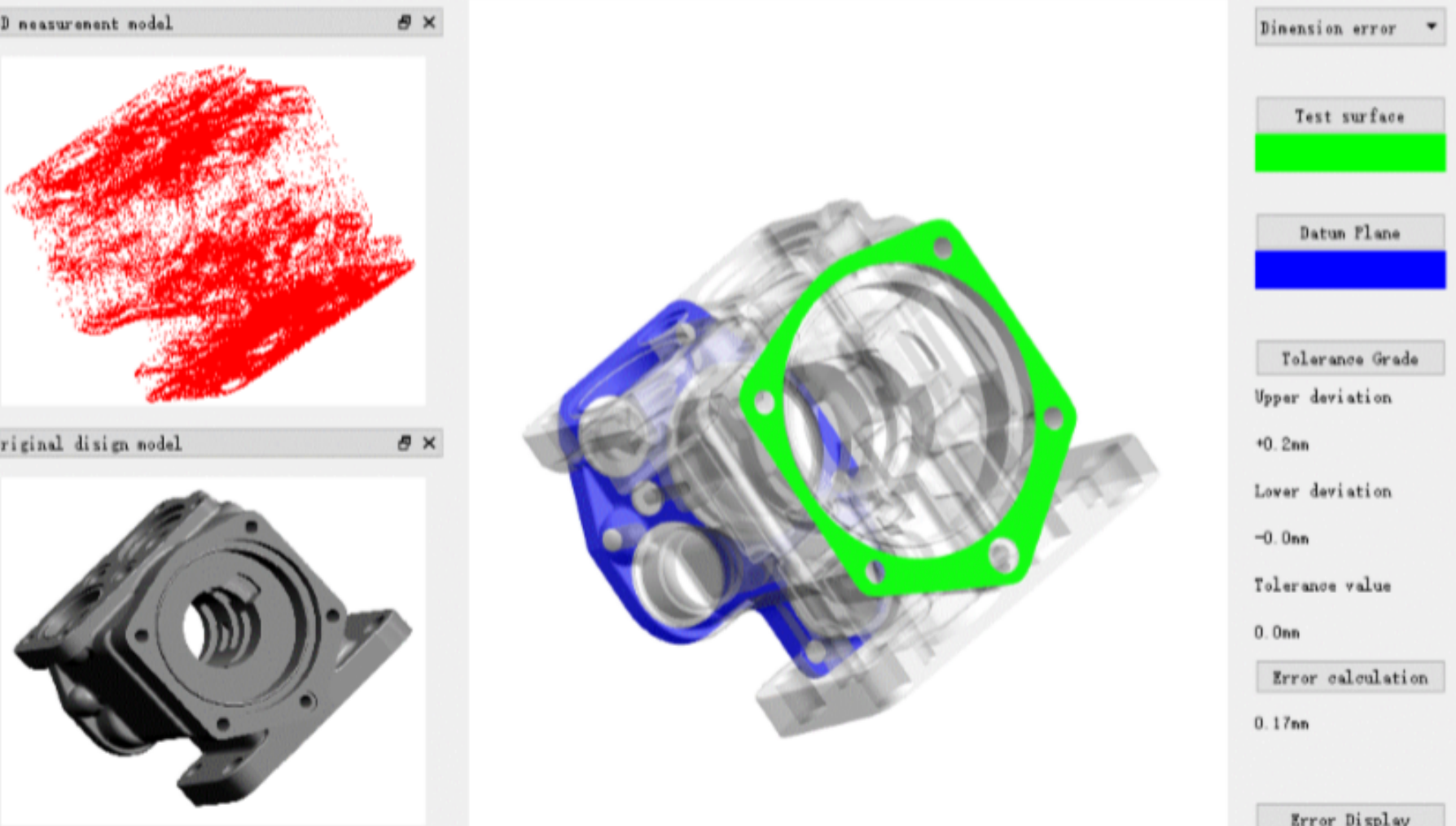

Toleranee Grade

Upper deviation

+0. 2 nn

Lover deviation

$-0.0 \mathrm{nn}$

Toleranee value

0. Onn

Error ealeulation

$0.17 \mathrm{nn}$

Zrror Display

\section{Figure 17}

Dimension error analysis results of the width of the valve body 


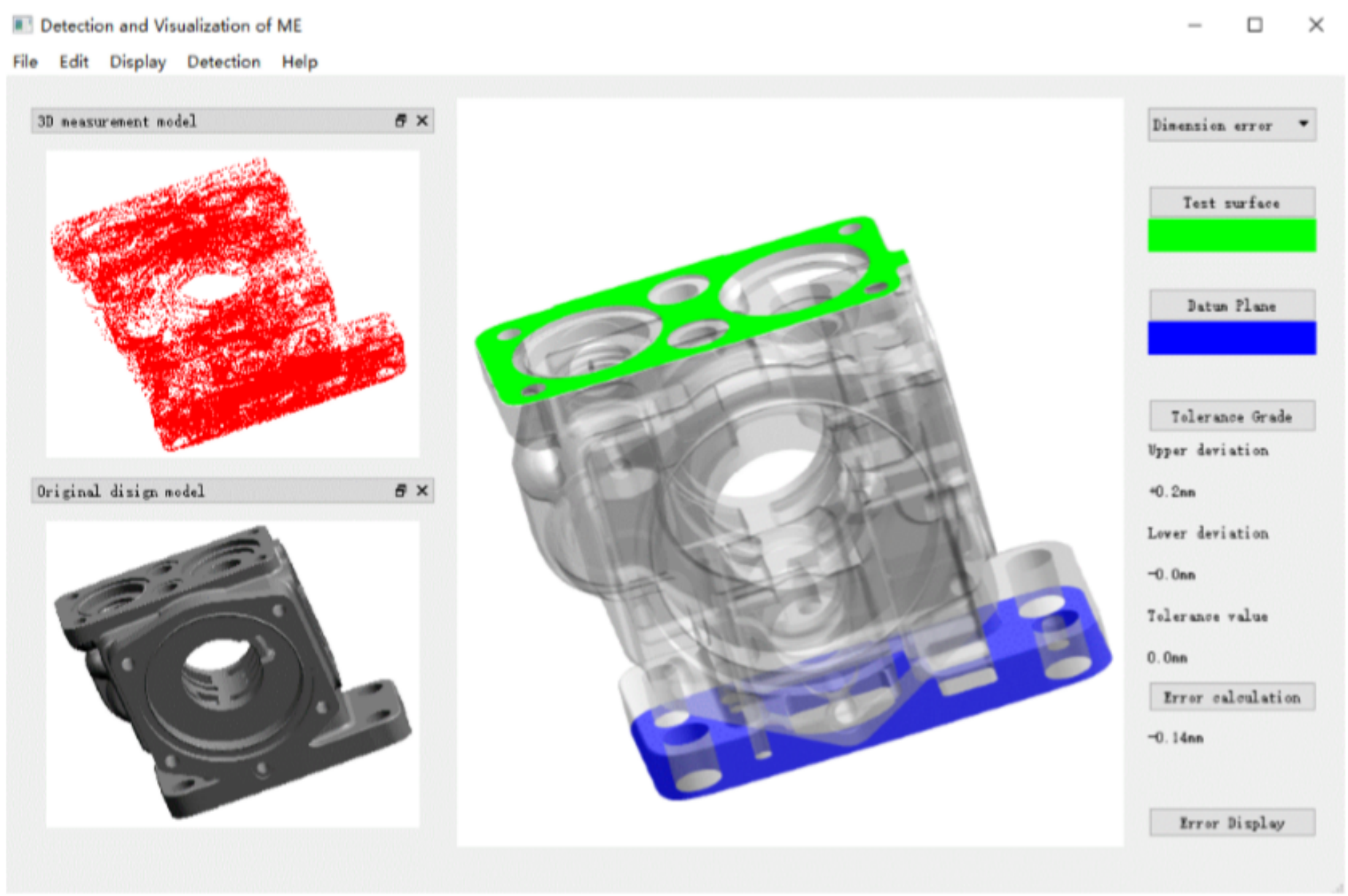

Figure 18

Dimension error analysis results of the height of the valve body 


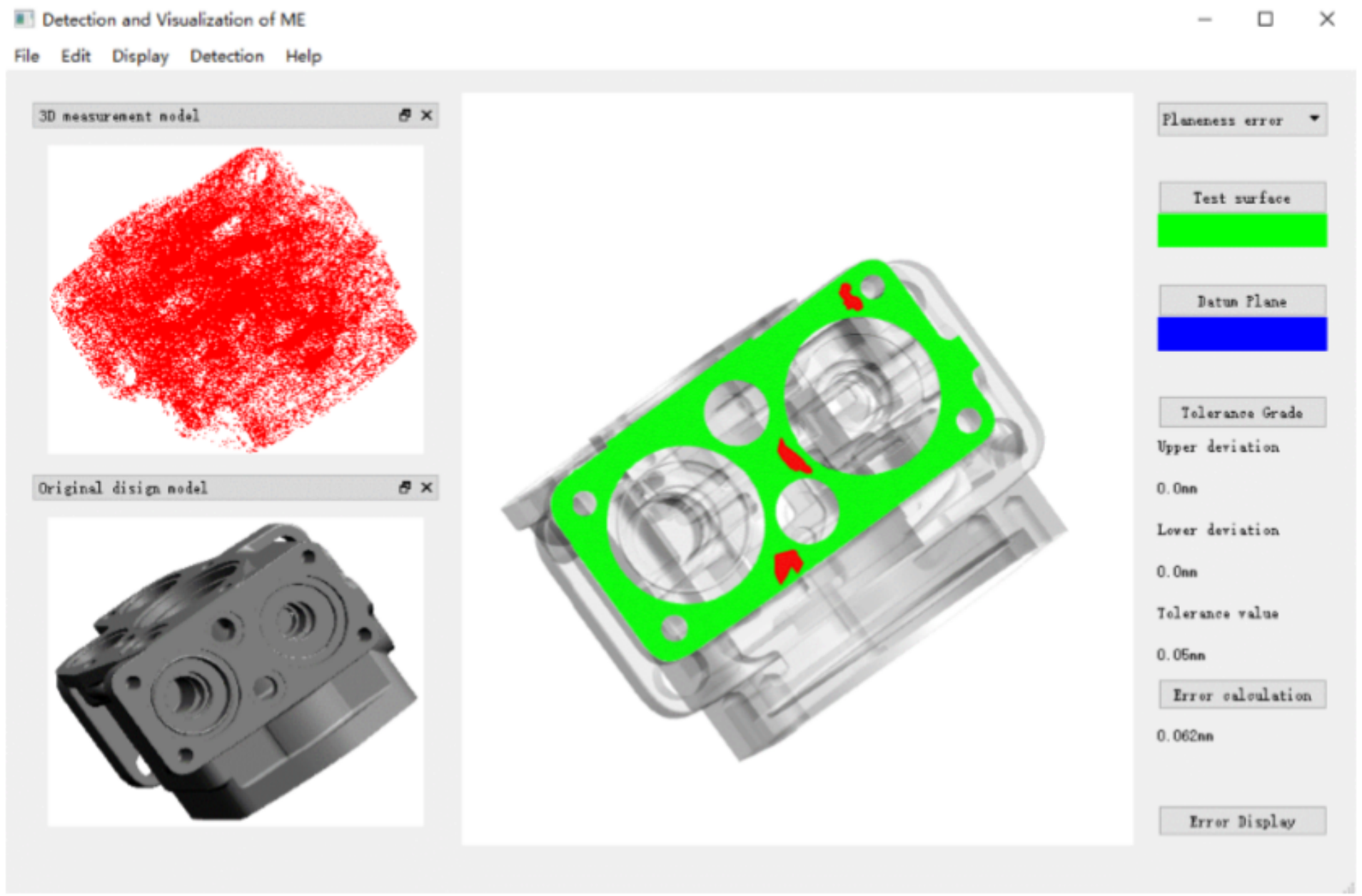

\section{Figure 19}

Analysis result of planeness error on upper surface of valve body base 


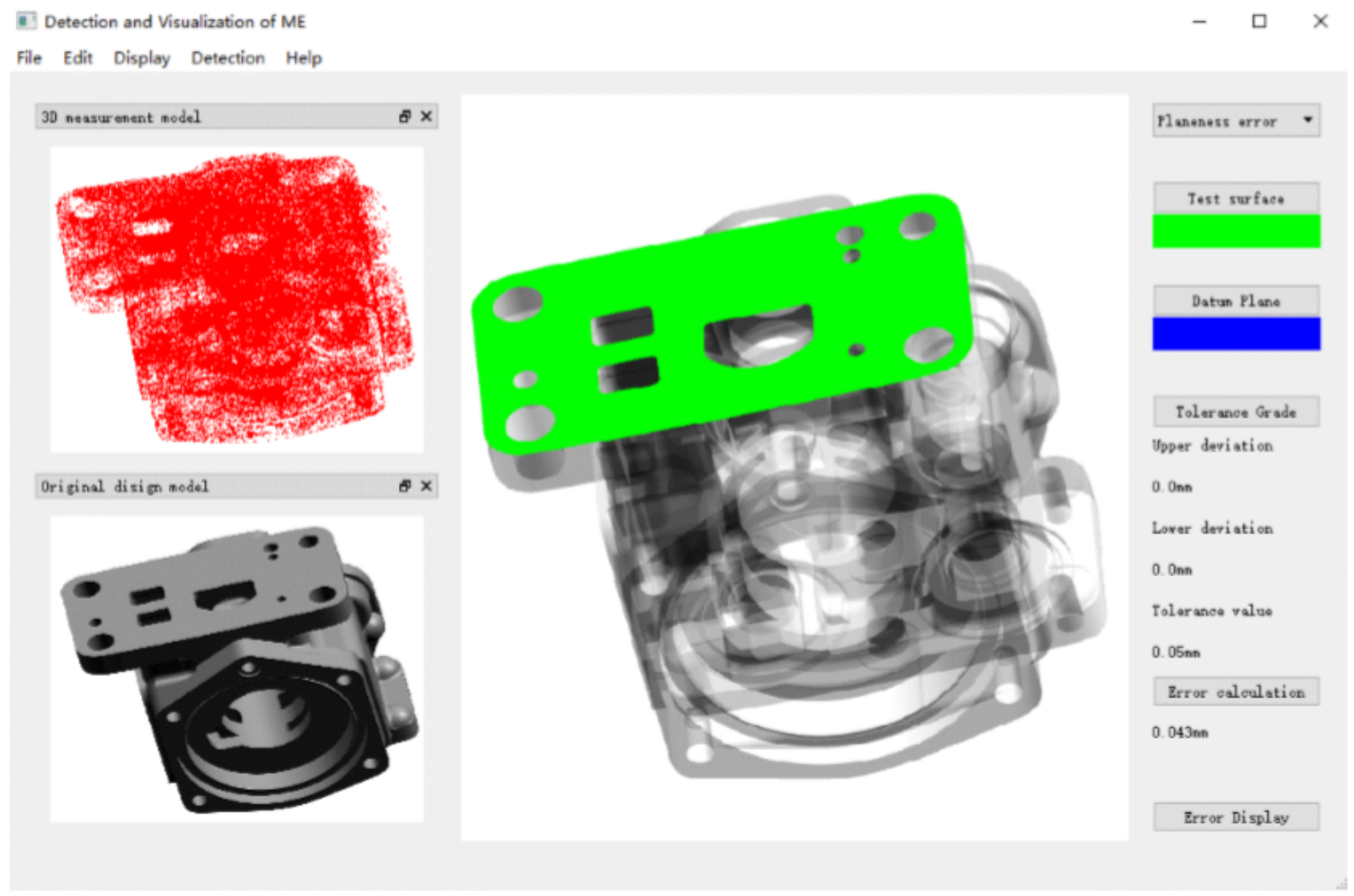

\section{Figure 20}

Analysis result of planeness error of the lower surface of the valve body base 


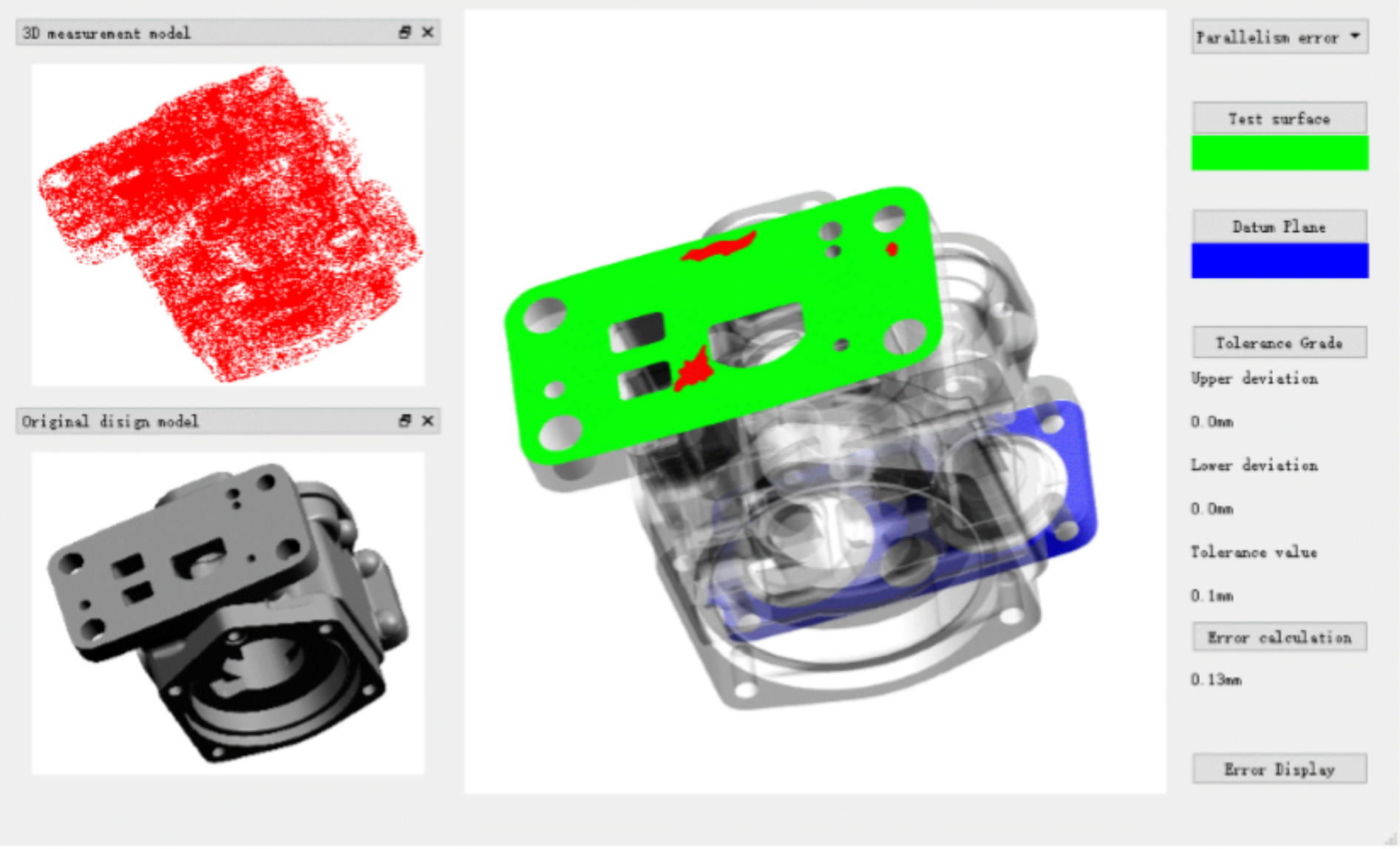

Figure 21

Analysis result of the parallelism error of the upper and lower surfaces of the valve body base 


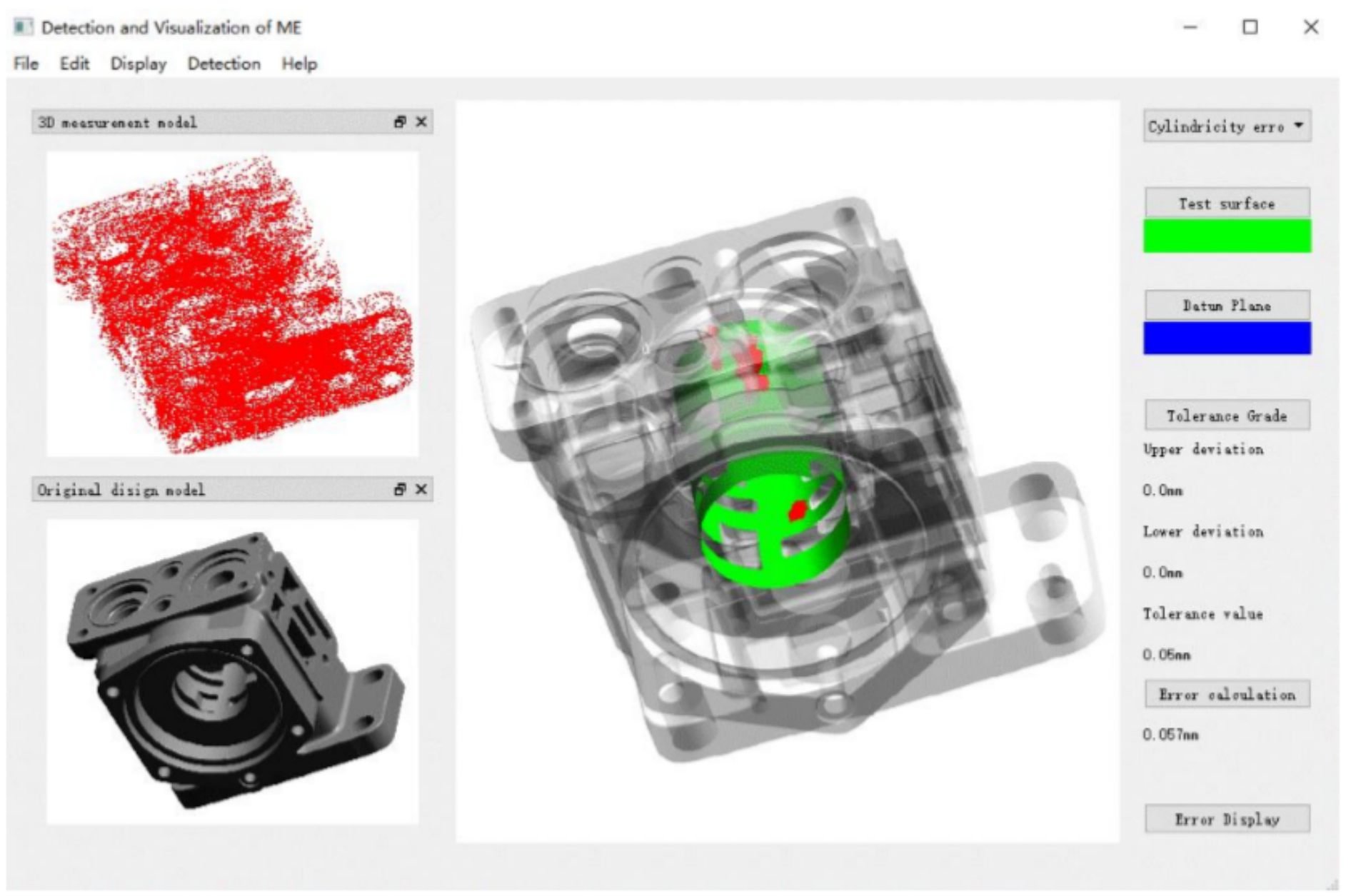

\section{Figure 22}

Cylindrical error analysis result of horizontal hole in valve body cavity 


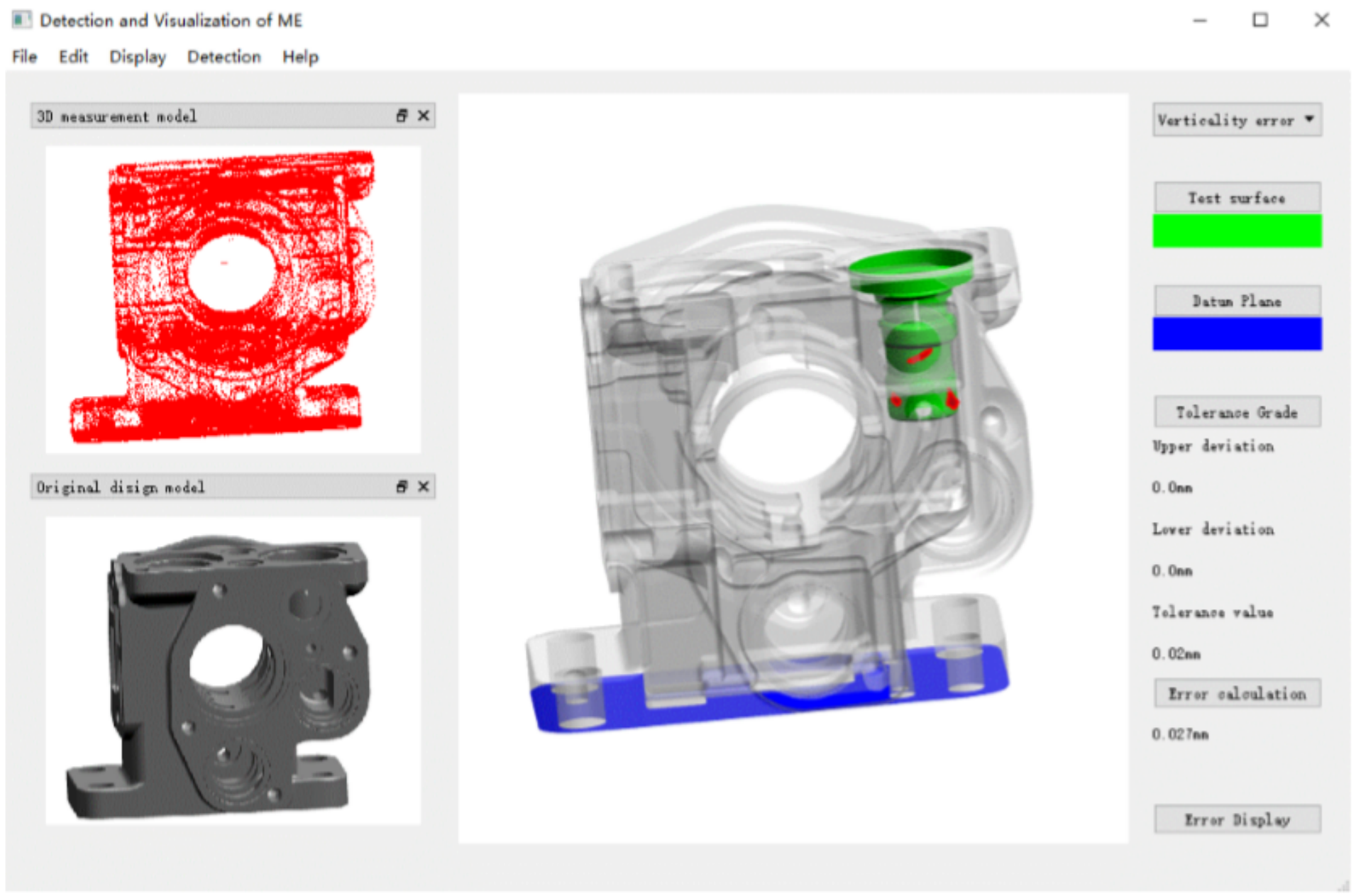

Figure 23

Analysis result of verticality error of the oil inlet No. 1 


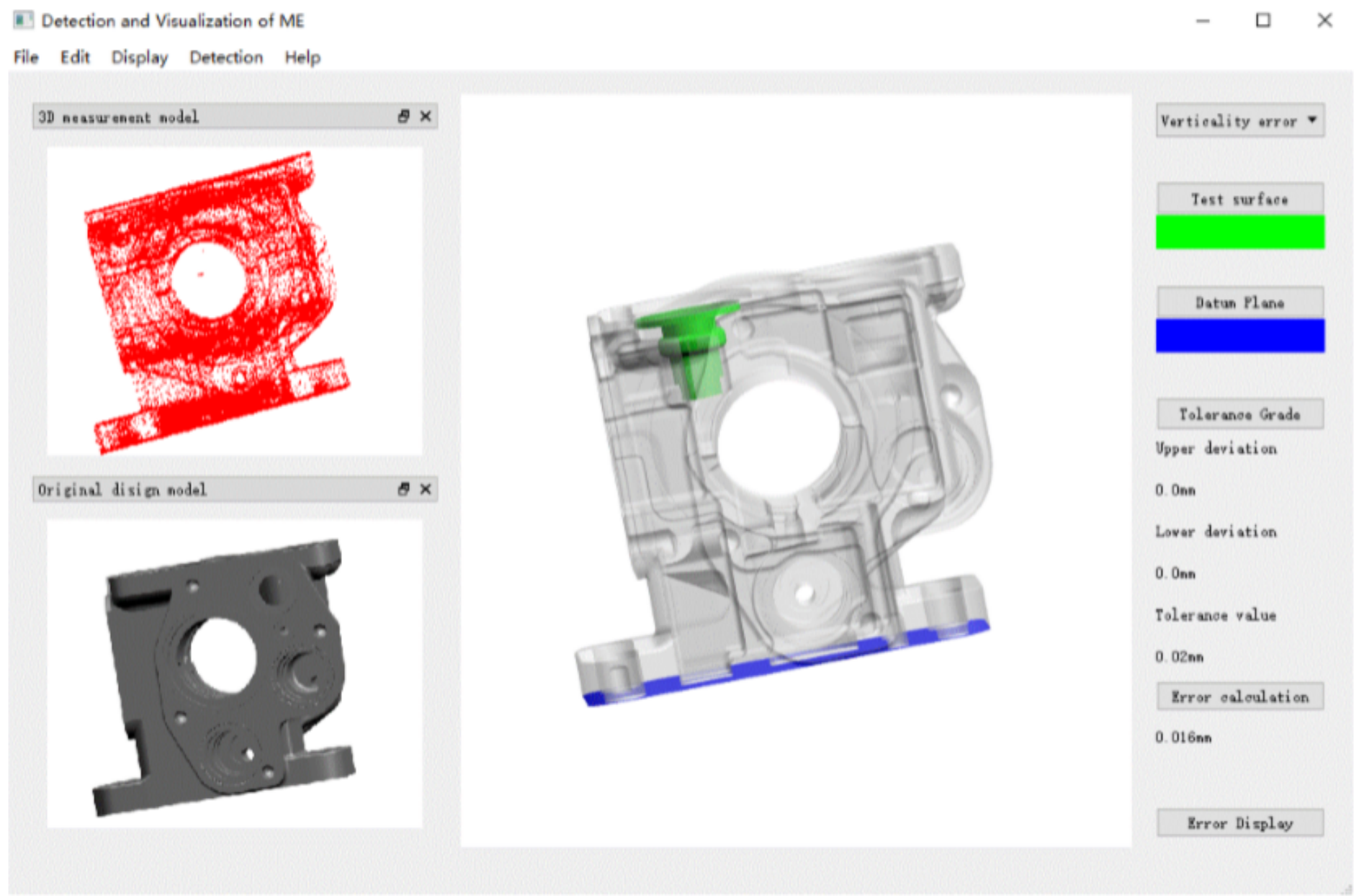

Figure 24

Analysis result of verticality error of the oil inlet No. 2 